\title{
Mathematical Modeling and Numerical Simulation of Splat Cooling in Plasma Spray Coatings
}

\author{
H. Fukanuma, R. Huang, Y. Tanaka, and Y. Uesugi
}

(Submitted January 29, 2009; in revised form July 6, 2009)

\begin{abstract}
Particle deformation and cooling significantly affect the characteristics of thermally sprayed coatings, such as the adhesion and cohesion strength between a splat and a substrate and between splats, as well as the internal stresses of deposits. It is essential to understand these processes for the successful industrial application of thermal spray technology. However, to date, the microstructure of the boundary of a splat and the substrate has not been clarified, although much research has been conducted on splat formation and the cooling process. We have developed a microstructure model of the boundary between the splat and the substrate, based on splat morphology obtained from experiments. In the model, it is assumed that gaps, or voids, and contact areas are arranged on the splat boundary with the substrate in an orderly fashion. The model includes phase changes and heat resistance simulating the function of the microstructure during splat cooling. Assumptions in the model are that ambient gas trapped in the gaps, or voids, transfers heat only by conduction and not by convection or radiation. The results of the simulation indicated that the extent of gaps, or voids, significantly affects the rate of decrease of the average temperature of the splat surface, as well as the temperature distribution inside the splat.
\end{abstract}

Keywords microstructure of splat/substrate boundary, modeling, splat morphology, splats cooling

\section{Introduction}

The deformation of a splat and its cooling affect adhesion, cohesion, porosity, and residual stress of plasma sprayed deposits. It has been shown that adhesion and cohesion are influenced by the characteristics of the impinging particles such as velocity and molten state, as well as by the substrate characteristics, such as temperature and oxidative state (Ref 1). Bahbou et al. (Ref 2) have shown that substrate conditions influence the cooling rate of particles, as well as the flattening speed. Arata et al. (Ref 3) have reported that plasma sprayed deposits contain gaps (nonbonded interfaces) between splats. By measuring the curvature of a substrate in situ during plasma spraying, Kuroda et al. (Ref 4) have shown that the tensile stress depended on substrate temperature, as well as spray materials and characteristics.

Research on splat morphology and flattening ratios as well as particle splash has been conducted (Ref 5-10). Fukumoto et al. (Ref 5,6) have suggested that above a certain temperature, molten particles do not splash when they impinge on a smooth flat surface. Li (Ref 7) has

H. Fukanuma and R. Huang, R\&D, Plasma Giken Co., Ltd., Tokyo, Japan; and Y. Tanaka and Y. Uesugi, Department of Electrical and Electronic System, Kanazawa University, Kanazawa, Japan. Contact e-mail: fukanuma@plasma.co.jp.

indicated that substances adsorbed on a substrate cause splat splashing because of evaporation resulting from heating by the molten droplet during its spreading.

Splat cooling rates during thermal spray coating processes depend significantly on the microstructure of the interface between the splat and the substrate, and on the splat and substrate materials (Ref 1,2,11, 12). Trapped ambient gas in pores, or gaps, causes heat resistance that affects the splat cooling rates. Although many studies have been conducted on splat forming and cooling, few studies

\begin{tabular}{|ll|}
\hline & \multicolumn{1}{c|}{ Nomenclature } \\
\hline$T$ & temperature \\
$T_{0}$ & initial temperature \\
$T_{\mathrm{p}}$ & splat surface temperature \\
$L_{\mathrm{m}}$ & latent heat of solidification \\
$T_{\mathrm{m}}$ & melting temperature \\
$k$ & thermal conductivity \\
$c$ & specific heat \\
$r, \theta, z$ & coordinates \\
$t$ & time \\
$R_{\mathrm{p}}$ & splat radius \\
$R_{0}$ & radius of center contacting area of splat \\
$R_{\mathrm{s}}$ & substrate radius \\
$H_{\mathrm{p}}$ & splat thickness \\
$h$ & gap depth \\
$H_{\mathrm{s}}$ & substrate thickness \\
$\varphi$ & central angle of trench \\
$\psi$ & angle of distributing trenches \\
$T_{\mathrm{av}}$ & average temperature on splat top face \\
$S$ & splat top area \\
\hline
\end{tabular}


have focused on the microstructure of the boundary between a splat and the substrate. Moreover, to date, actual contact ratios of splat/substrate boundary and defects such as gaps, or pores, on the boundary have not been clarified. Amara et al. (Ref 13) have presented a three-dimensional (3D) computational model of heat transfer between a splat and a substrate based on a splat/substrate interface model, in which contact spots were randomly distributed. The model indicated that when the contact was perfect, the thermal conductivity was equal to that of the substrate materials, whereas when it was imperfect, the thermal conductivity was equal to that of the gas trapped in the noncontact areas. McDonald et al. (Ref 11) have studied a one-dimensional heat conduction model with uniform thermal contact resistance between the splat and substrate. The thermal resistance of the splat/substrate interface was determined based on the model by experiments that measured $\mathrm{Mo}$ and $\mathrm{ZrO}_{2}$ splat cooling rates on glass and Inconel substrates.

In this study, we first sprayed metal particles onto glass substrates and photographed the splat patterns. Then, a splat/substrate boundary model was developed by simplifying the complicated morphology of the splat bottom faces we observed. The splat bottom face was divided into two parts consisting of perfect contact and noncontact areas that were placed on the face in an orderly way. It was assumed that the noncontact regions were filled with ambient gas. In order to clarify how different the temperature, or cooling rate, is between the portion above the perfect and that above the imperfect contact boundary, a mathematical model was developed. This model was based on the interface model that included phase changes. A 3D simulation was conducted to see how the model functioned.

\section{Modeling of Splat Cooling}

\subsection{Splat/Substrate Interface Model}

Nickel (Ni), aluminum (Al), and molybdenum (Mo) particles were sprayed onto smooth flat glass substrates with a SG-100 plasma torch (Praxair, Inc., Danbury, CT, USA), and the top and bottom views of captured splats were photographed. Both top and bottom views of typical splat examples obtained from our plasma spray experiments are shown in Fig. 1. The photographs in Fig. 1 show the top and bottom faces of $\mathrm{Ni}, \mathrm{Al}$, and Mo splats: (a) and (b) show the top and bottom views of a Ni splat, respectively. Figure 1(c) and (d) show top and bottom views of $\mathrm{Al}$, and Fig. 1(e) and (f) top and bottom views of Mo splat. Many trenches or ditches are clearly seen extending from the centers of the $\mathrm{Ni}$ and $\mathrm{Al}$ splats to their peripheries in the bottom views in (b) and (d) of Fig. 1. No such trenches are seen in the photographs of the top views. It appears that in these trenches the bottom of the splat does not contact the glass substrates. The trenches may be generated by ambient gas that was trapped under the particle because the flattening speed was too fast to blow the gas out from under the particle. Fine lines or trenches, however, are seen in both top and bottom views of the Mo splat. The lines on the top face might be generated in a different way from the ones on the bottom face. We do not understand how the fine lines on the top were formed. The fine lines on the bottom face could have formed as a result of the long time taken for the molten molybdenum particle to solidify; therefore, the lines became finer because most of the initially trapped gas gradually escaped from beneath the particle by the time the solidification was completed. In any event, there are radial trenches, or lines, running on the bottom view of every splat. On the other hand, none of the center areas of the bottom views had trenches, and those central areas made contact with the substrates, albeit some small defects that could be seen.

We developed a splat morphological model on the basis of the results of the above experiments. In this model, radial trenches stretch on the bottom face of the splat as shown in Fig. 2, under the assumption that at the moment when the flattening process of the particle finished (no further expansion), the splat morphology was completed, or fixed, even if the material was in a molten state.

In the model, the outer radius and thickness of the splat were $R_{\mathrm{p}}$ and $H_{\mathrm{p}}$, respectively. We created a trench by aggregating some finer trenches shown in the bottom view of the splat. The dimensions of the trench were defined: the central angle of the sector, the depth, and the length were $\varphi, h$, and $R_{\mathrm{p}}-R_{0}$, respectively, where $R_{0}$ was the radius of the inner contact area. Each trench was distributed at every angle of $\psi$ over the splat. The substrate radius and thickness were $R_{\mathrm{s}}$ and $H_{\mathrm{s}}$ in the coordinate system as is shown in Fig. 3.

\subsection{Mathematical Modeling and Solution Method}

The splat and substrate temperature $T$ a function of time $t$ is written in cylindrical coordinates:

$$
\rho c \frac{\partial T}{\partial t}=k\left(\frac{\partial^{2} T}{\partial r^{2}}+\frac{1}{r} \frac{\partial T}{\partial r}+\frac{1}{r^{2}} \frac{\partial^{2} T}{\partial \theta^{2}}+\frac{\partial^{2} T}{\partial z^{2}}\right)-\rho L_{\mathrm{m}} \frac{\partial f_{\mathrm{L}}}{\partial t}
$$

where $\rho, c, k, L_{\mathrm{m}}$, and $f_{\mathrm{L}}$ are density, specific heat, thermal conductivity, latent heat, and local liquid fraction, respectively. The last term in Eq 1 shows that phase changes are taken into consideration in the splat solidification process using the enthalpy method (Ref 13,14$)$. In the numerical calculation, the solidification temperature range was taken as $10{ }^{\circ} \mathrm{C}$ between $\left(T_{\mathrm{m}}+9\right)$ and $\left(T_{\mathrm{m}}-1\right)$ in order to save calculation time. It was assumed that the radiative and convective heat transfer from plasma jet to the splat/substrate system was negligible; therefore the boundary condition of the top face of the system and the splat side face was adiabatic. The heat transfer through the interfaces between the gas trapped in the trenches and the splat or the substrate was assumed to be conductive with neither convection nor radiation in the trenches. It was also assumed that the boundary conditions of the cylindrical and bottom walls of the substrate were at a constant temperature. Figure 4 illustrates the boundary conditions so the reader can quickly comprehend the complicated 

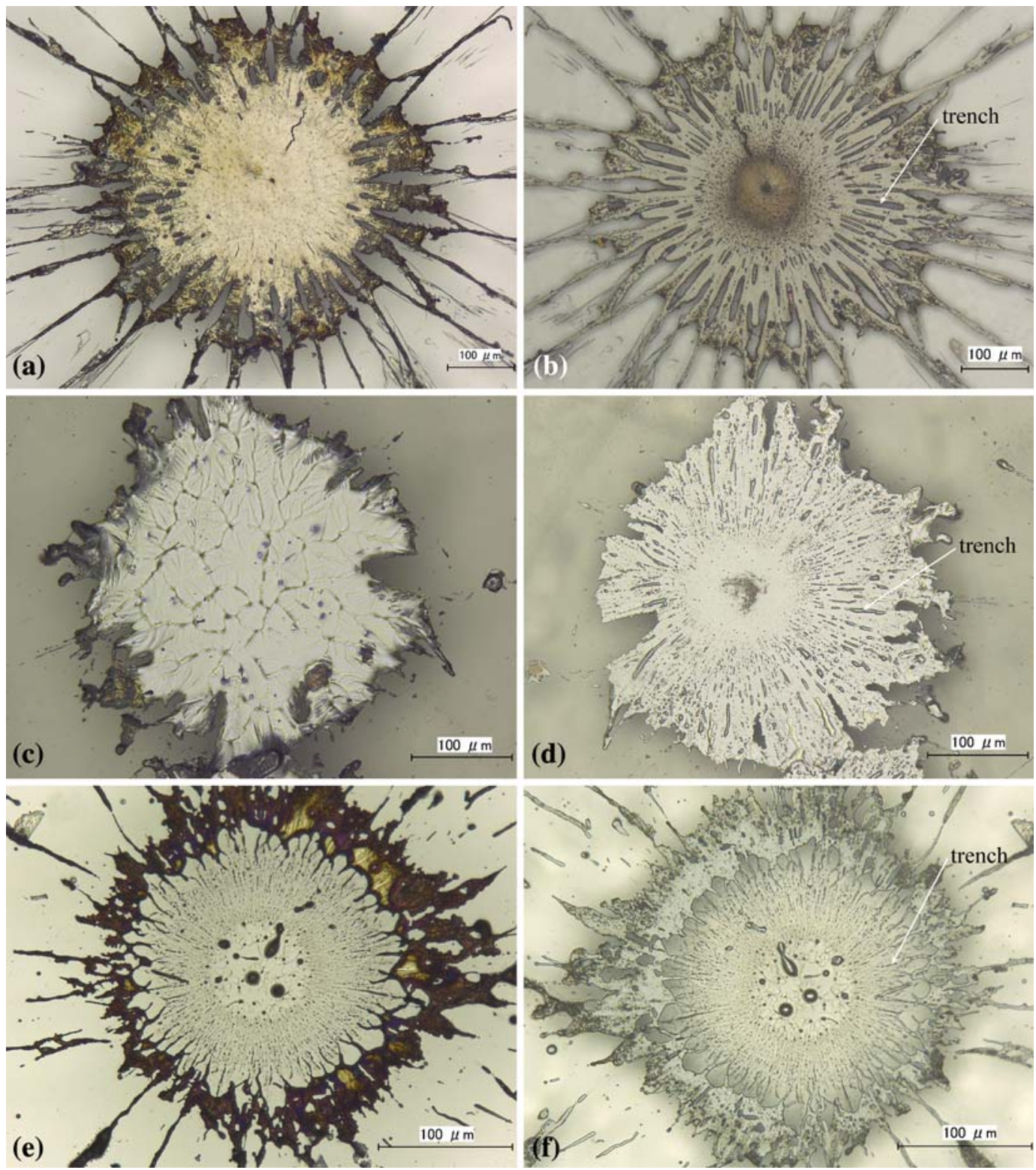

Fig. 1 Splat morphology of $\mathrm{Ni}, \mathrm{Al}$, and Mo on glass, top face view in (a), (c), and (e), and bottom face view in (b), (d) and (f), respectively

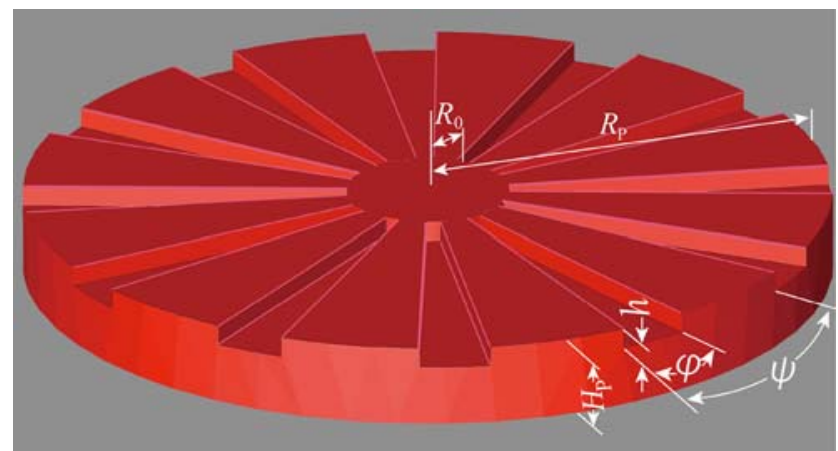

Fig. 2 Bottom view of a splat model developed based on $\mathrm{Ni}$ splat on glass substrate

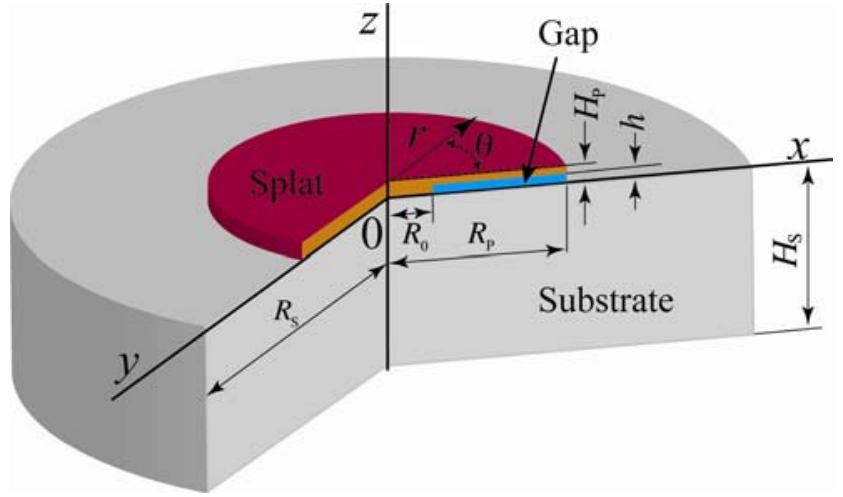

Fig. 3 Coordinates and the dimensions of splat, gap, and substrate

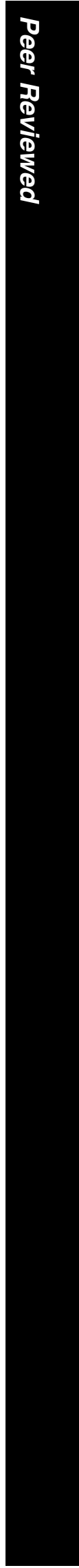




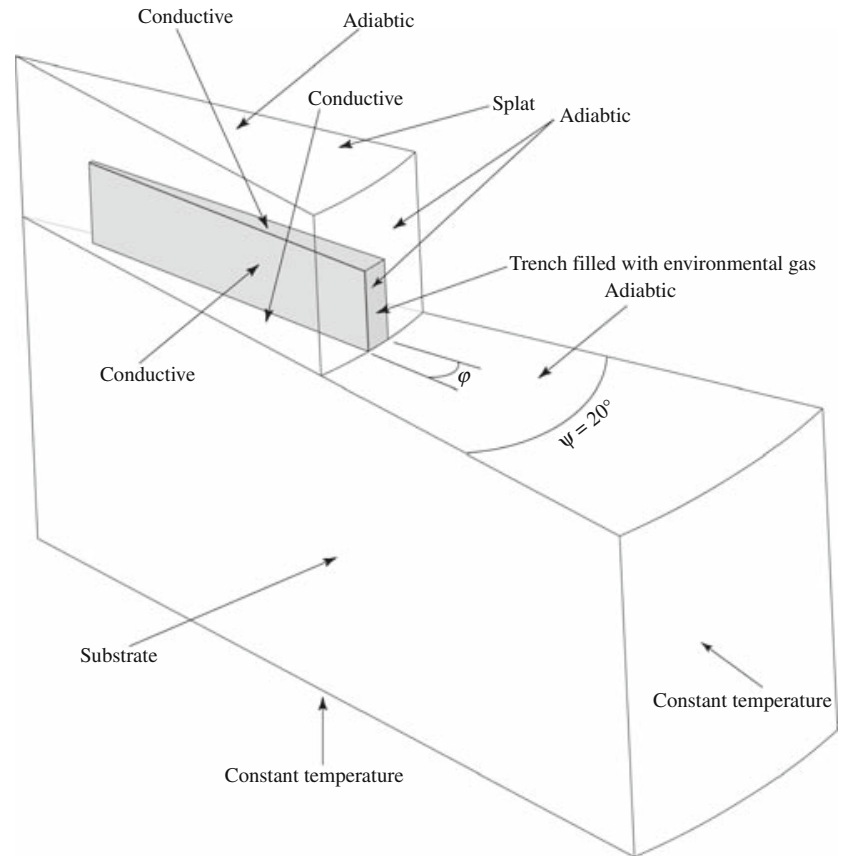

Fig. 4 Illustration of the boundary conditions of the splat, the ambient gas trapped in the trench and substrate

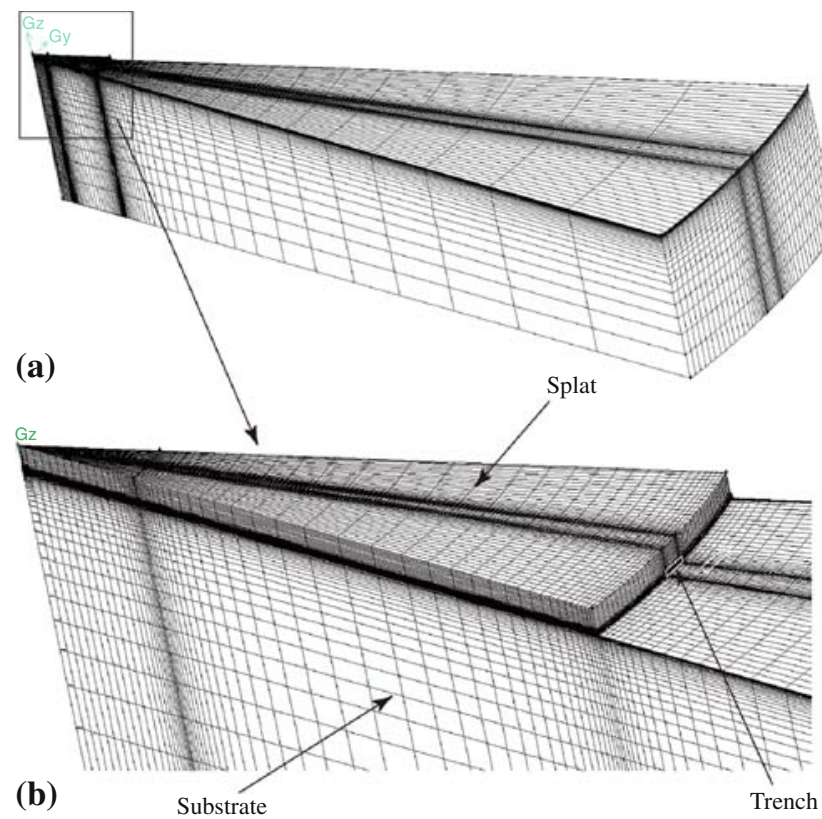

Fig. 5 Calculation domain. (a) Entire splat, trench, and substrate system. (b) Enlarged part to show the detail of the splat and the trench conditions mentioned previously. The calculation domain is shown in Fig. 5. The number of cells was 347,072 in the domain. The time step for computation was $10^{-9} \mathrm{~s}$.

The simulations were conducted with commercially available software, Fluent 6.3 (ANSYS, Inc., Canonsburg, PA, USA), which uses finite volume schemes. Thermophysical properties of materials and the dimensions of the splat/substrate system are shown in Table 1 and 2, respectively. We selected four central angles " $\varphi$ " of $0,2,6$, and $10^{\circ}$ for the computation. At these angles, the ratios of the splat making contact with the substrate were 100, 90.4, 71.2 , and $52.0 \%$, respectively. The contact ratios were obtained by the formula:

Contact ratio $=\frac{\pi\left(R_{\mathrm{p}}^{2}-R_{0}^{2}\right)}{\pi R_{\mathrm{p}}^{2}} \frac{\varphi}{360} \frac{360}{\psi}=\frac{\left(R_{\mathrm{p}}^{2}-R_{0}^{2}\right)}{R_{\mathrm{p}}^{2}} \frac{\varphi}{\psi}$

\section{3D Computational Simulation Results and Discussion}

Images of the computational results for the temperature distributions in cross section of the splat and substrate systems including the trench with an angle " $\varphi$ " of $0,2,6$, and $10^{\circ}$ are shown in Fig. 6 . At $10^{-8} \mathrm{~s}$ after splat cooling began, the splat with $100 \%$ contact with substrate uniformly decreased in temperature. However, in the other three splats with imperfect contact with the substrates, the temperature fell around the center portions. At $10^{-7} \mathrm{~s}$, the temperatures in splats with 100 and $90.4 \%$ contact fell uniformly faster than those with 71.2 and $52.0 \%$ contact. The temperatures in the peripheries were much higher than those in the centers for $\varphi=6$ and $10^{\circ}$, because the

Table 1 Thermophysical properties of the materials for computation

\begin{tabular}{|c|c|c|c|c|c|c|}
\hline Material & $\begin{array}{c}k, \\
\mathbf{W} /(\mathbf{m} \cdot \mathbf{K})\end{array}$ & $\begin{array}{c}c, \\
\mathbf{J} /(\mathbf{k g} \cdot \mathbf{K})\end{array}$ & $\underset{\mathbf{k g} / \mathbf{m}^{3}}{\rho,}$ & $\boldsymbol{T}_{\mathrm{m}},{ }^{\circ} \mathrm{C}$ & $\begin{array}{l}L_{\mathbf{m}}, \\
\mathbf{J} / \mathbf{k g}\end{array}$ & $T_{0},{ }^{\circ} \mathrm{C}$ \\
\hline \multicolumn{7}{|l|}{ Splat } \\
\hline $\begin{array}{l}\text { Mo } \\
\text { Solid }\end{array}$ & 84 & 339 & 9340 & 2630 & $2.90 \times 10^{5}$ & \\
\hline $\begin{array}{l}\quad \text { Liquid } \\
\text { Substrate } \\
\text { Fe }\end{array}$ & 84 & 570 & 9340 & $\ldots$ & $\ldots$ & 3500 \\
\hline $\begin{array}{l}\text { Solid } \\
\text { Trench }\end{array}$ & 29.7 & 791 & 7015 & 1536 & $2.47 \times 10^{5}$ & 100 \\
\hline $\begin{array}{l}\text { Air } \\
\text { Gas }\end{array}$ & 0.0242 & 1006.4 & 1.225 & $\ldots$ & $\ldots$ & 3500 \\
\hline
\end{tabular}

Table 2 Dimensions of model splat and substrate

\begin{tabular}{llccccc}
\hline & $\begin{array}{c}\text { Radius, } \\
\boldsymbol{\mu m}\end{array}$ & $\begin{array}{c}\text { Thickness, } \\
\boldsymbol{\mu m}\end{array}$ & $\begin{array}{c}\text { Trench depth } \\
(\boldsymbol{h}), \boldsymbol{\mu m}\end{array}$ & $\begin{array}{c}\text { Central angle } \\
(\boldsymbol{\varphi}), \text { degrees }\end{array}$ & $\begin{array}{c}\text { Pitch angle } \\
(\boldsymbol{\psi}), \text { degrees }\end{array}$ & $\begin{array}{c}\text { Trench length } \\
\left(\boldsymbol{R}_{\mathbf{p}}-\boldsymbol{R}_{\mathbf{0}}\right), \boldsymbol{\mu m}\end{array}$ \\
\hline Splat & $R_{\mathrm{p}}=50$ & $H_{\mathrm{p}}=2$ & 0.2 & $0,2,6,10$ & 20 & 40 \\
Substrate & $R_{\mathrm{s}}=500$ & $H_{\mathrm{s}}=100$ & $\ldots$ & $\ldots$ & $\ldots$ & $\ldots$ \\
\hline
\end{tabular}



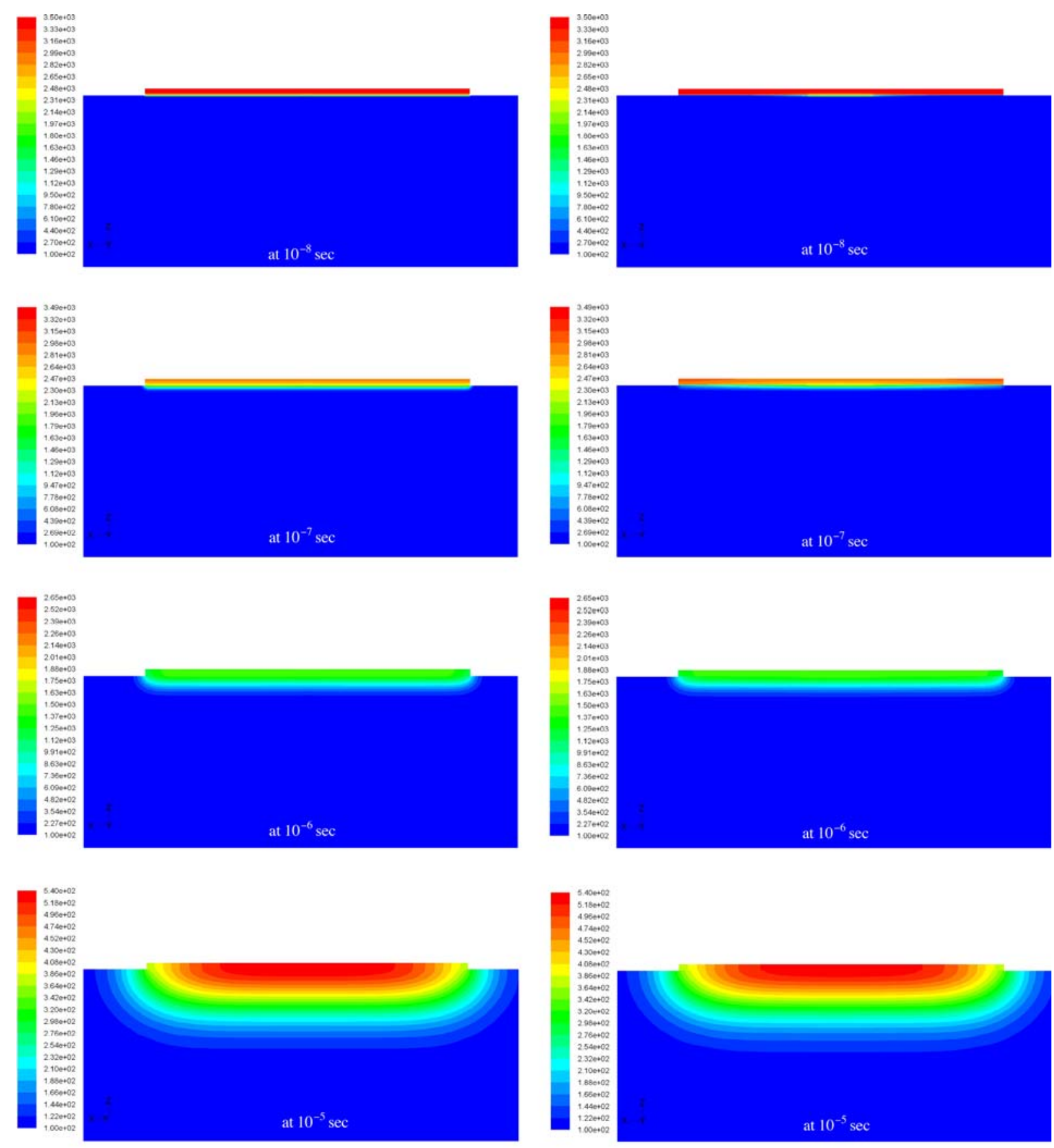

(a) contact ratio: $100 \%$

(b) contact ratio: $90.4 \%$

Fig. 6 Temperature distributions on the splat/substrate cross section of the splat for contact ratios of $100,90.4,71.2$, and $52.0 \%$ at $10^{-8}$, $10^{-7}, 10^{-6}$, and $10^{-5} \mathrm{~s}$

trenches resisted heat transfer. The peripheral temperatures of the splats were higher on the order of 52.0, 71.2, 90.4 , and $100 \%$ contact ratio. At $10^{-6} \mathrm{~s}$, the temperature of the splat with $100 \%$ contact fell almost uniformly to $1500{ }^{\circ} \mathrm{C}$ from the original temperature of $3500{ }^{\circ} \mathrm{C}$; the peripheral temperature of the $52.0 \%$ contact splat, however, was still higher than $2500{ }^{\circ} \mathrm{C}$. There was a difference of $1000{ }^{\circ} \mathrm{C}$ between the splats. It is clear that the heat resistance of air trapped in the trenches was significant.
At $10^{-5} \mathrm{~s}$, all the temperature distributions become nearly identical. It appears that when contact ratios are less than approximately $70 \%$, the temperature distribution in the splat becomes uneven. The simulations indicated that noncontact interfaces between splats and substrates significantly affected cooling rates.

Images of the temperature distribution on the upper side of the splats are shown at $10^{-7}, 10^{-6}$, and $10^{-5} \mathrm{~s}$ in Fig. 7. The temperature distribution of the splat making 

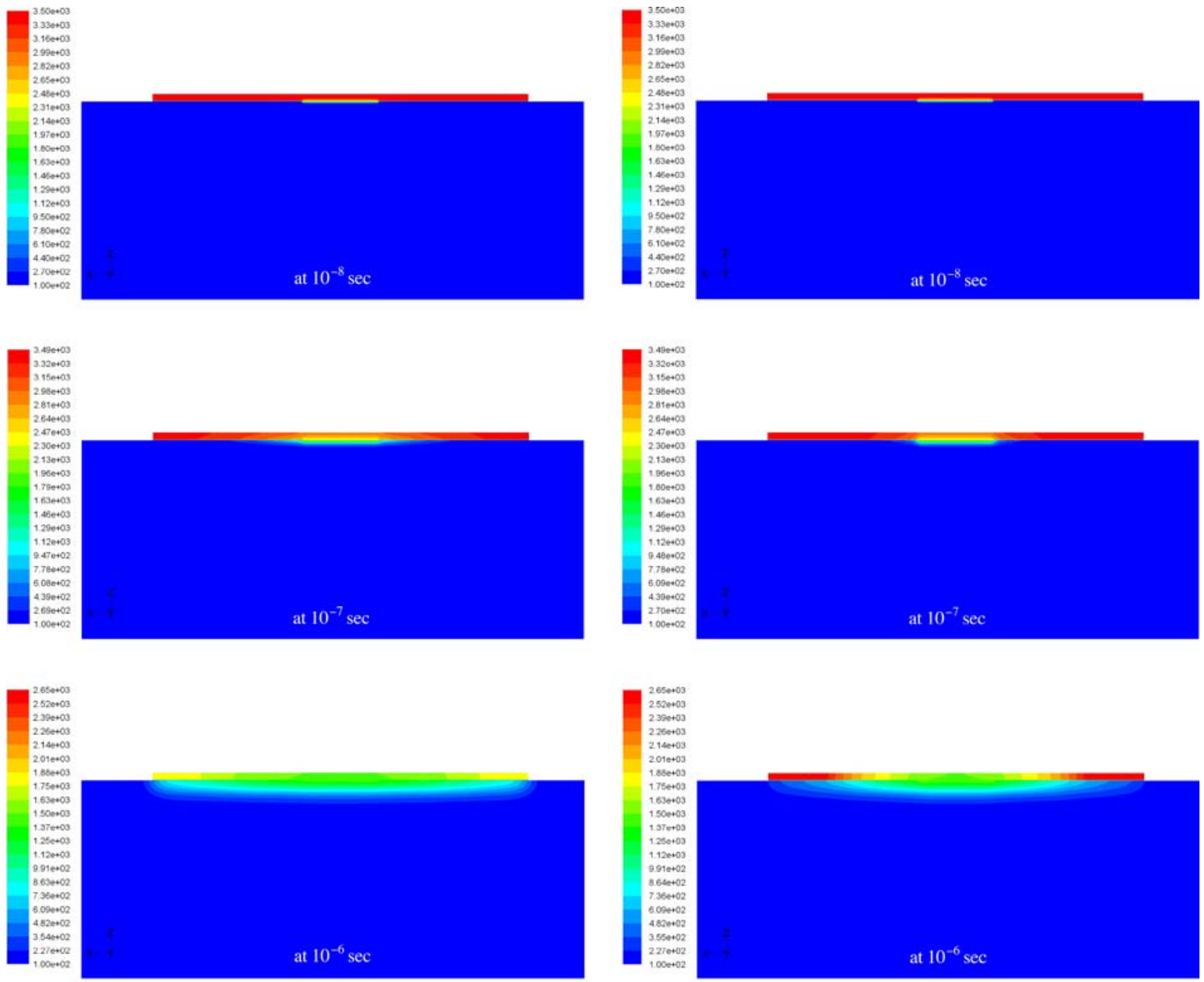

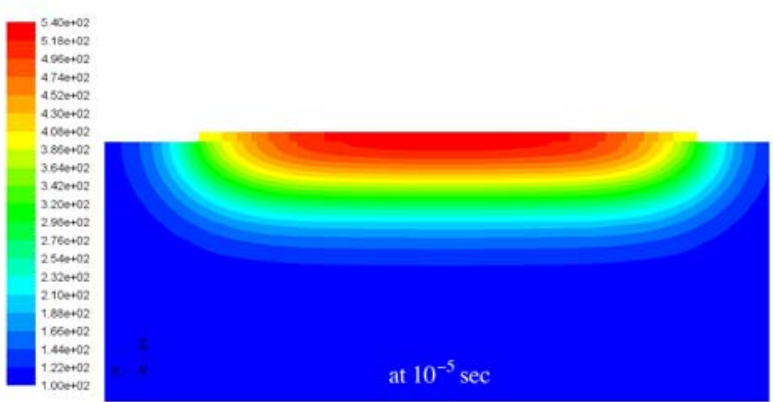

(c) contact ratio: $71.2 \%$
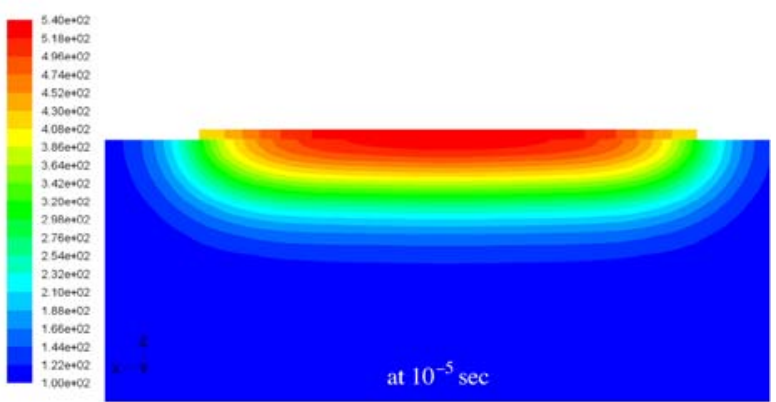

(d) contact ratio: $52.0 \%$

Fig. 6 Continued

perfect contact with the substrate shows that the temperature differences on the top were less than $200{ }^{\circ} \mathrm{C}$ at each time period. Moreover, in these splats, the temperature of the periphery was lower than that of the center. On the other hand, for the splat with $52.0 \%$ contact, the temperature differences on the top were more than $500{ }^{\circ} \mathrm{C}$ at $10^{-7} \mathrm{~s}$ and about $1000^{\circ} \mathrm{C}$ at $10^{-6} \mathrm{~s}$. The temperature above a trench was much higher than that above a contact point. It can be seen that at $10^{-7}$ and $10^{-6} \mathrm{~s}$ the temperature distribution images for the top were identical to the configuration of trenches. Moreover, the temperature of the periphery, above the trench, was much higher than that of the center. At $10^{-5} \mathrm{~s}$, the temperature of the periphery became lower than that of the center for all contact ratios.

In Fig. 8, the average temperatures on the top faces with $100,90.4,71.2$, and $52.0 \%$ contact with the substrate are shown against the passage of time. It is clear that the cooling rates for the splats with 100 and $90.4 \%$ contact were identical. The cooling rates for the splats with 71.2 

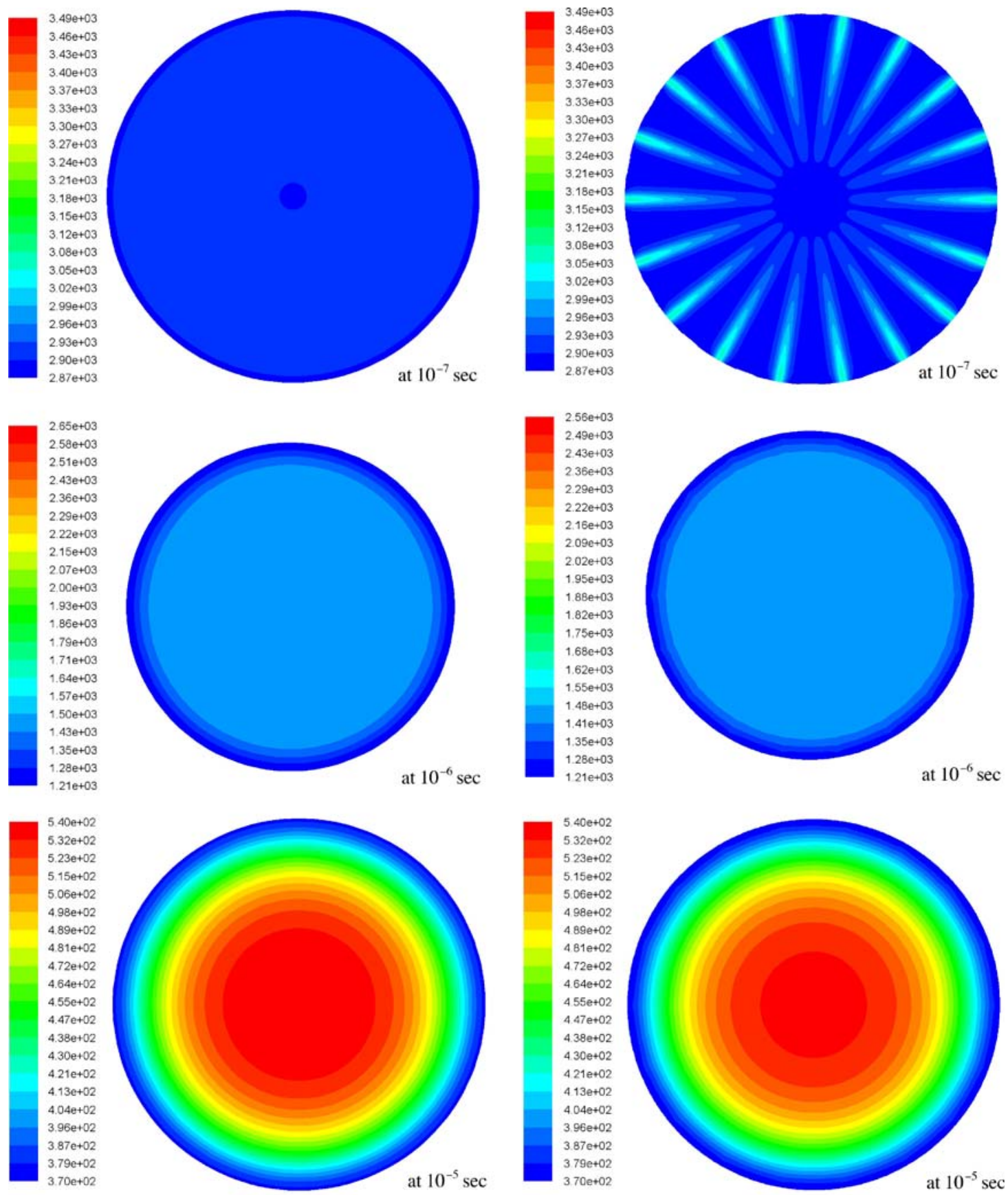

(a) contact ratio: $100 \%$

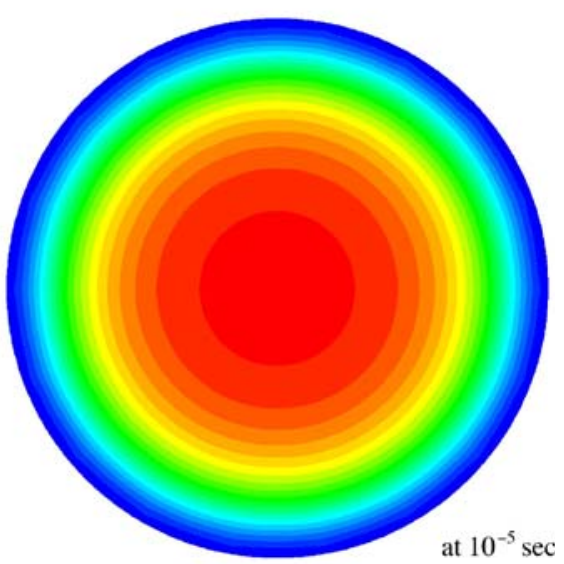

(b) contact ratio: $90.4 \%$

Fig. 7 Temperature distributions on the top face of the splat for contact ratios of $100,90.4,71.2$, and $52.0 \%$ at $10^{-7}, 10^{-6}$, and $10^{-5} \mathrm{~s}$

and $52.0 \%$ contact were slower than those for the splats with 100 and $90.2 \%$ contact. The average surface temperature of the splat with $52.0 \%$ contact decreased more slowly. The temperature on the splat with $52.0 \%$ contact was nearly $500{ }^{\circ} \mathrm{C}$ higher than that on the splat with $100 \%$ contact after about $0.5 \mu \mathrm{s}$. The gradient for the curves was gradual at 0.1 to $0.5 \mu$ s because of the effect of latent heat. The influence of latent heat on cooling time was relatively small, because the time to needed to solidify was only 0.1 to $0.2 \mu \mathrm{s}$. The definition of the average temperature $T_{\mathrm{av}}$ is written:

$T_{\mathrm{av}}=\frac{\int_{\mathrm{S}} T_{\mathrm{p}} d s}{S}$

where $T_{\mathrm{p}}$ is the top surface temperature of the splat and $S$ is the area of the top surface.

The splat temperature cooling curves at the center and at the periphery above the contact and the 

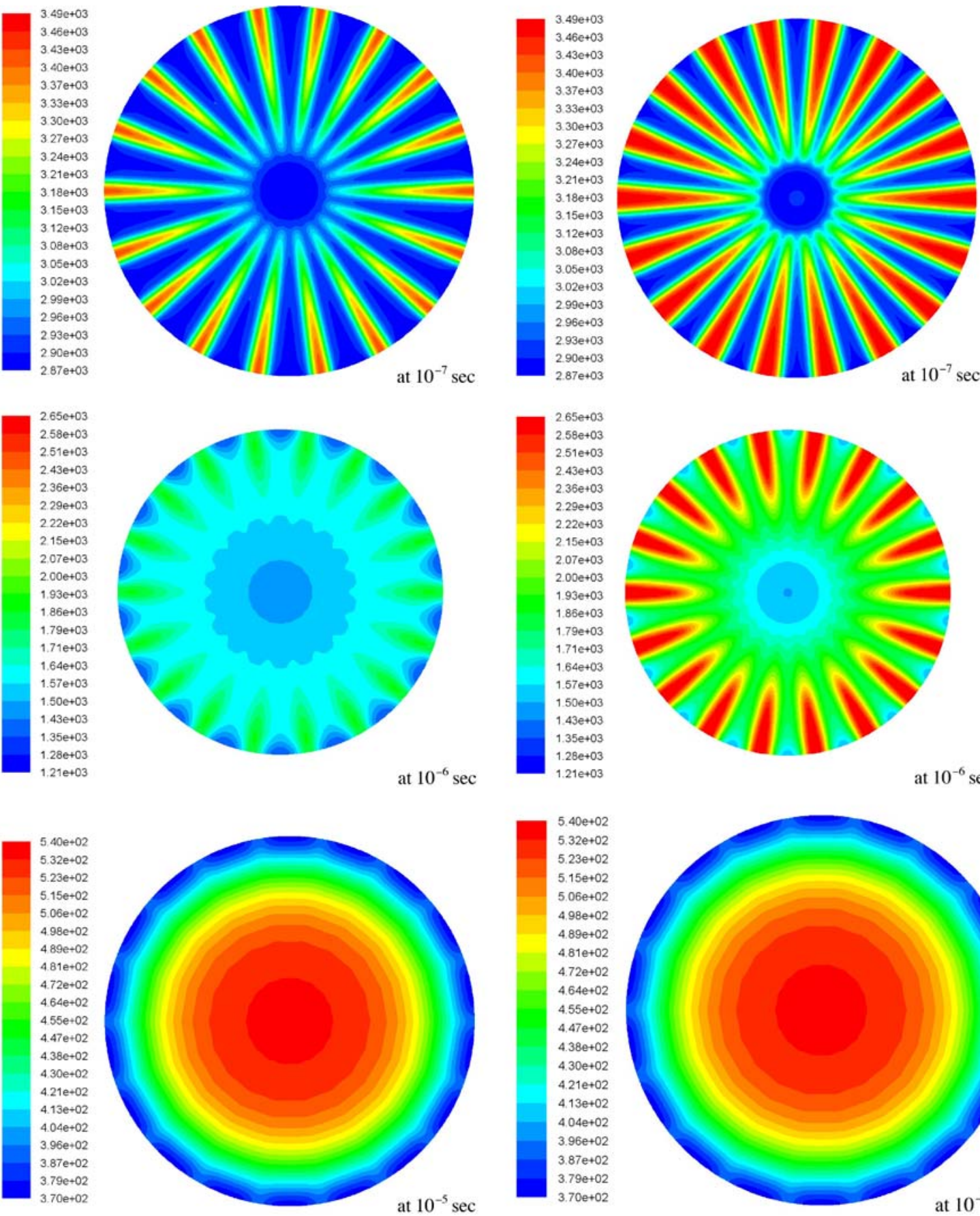

(c) contact ratio: $71.2 \%$

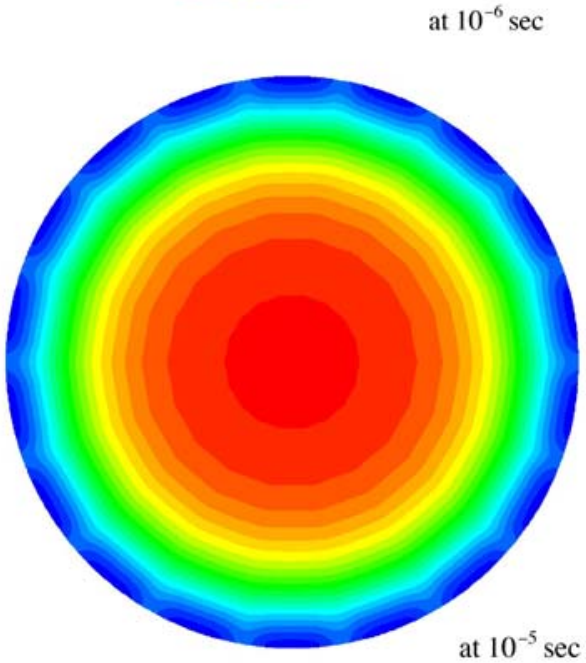

(d) contact ratio: $52.0 \%$

Fig. 7 Continued

noncontact points are shown for the splat with $52.0 \%$ contact in Fig. 9. It can be seen that the temperature on the periphery above the noncontact point fell slowly compared with that at other points until $3 \mu \mathrm{s}$, then, it became similar to that of other points, and finally the temperature became lower than that of the center. The temperature was significantly higher than that of the other points until nearly $2 \mu \mathrm{s}$ and the temperature deference was more than $1000{ }^{\circ} \mathrm{C}$ around $1 \mu \mathrm{s}$. This indicates that the trenches or gaps filled with ambient gas play a critical role in the splat cooling process. Figure 10 shows that from the start, the temperature at the rim of the splat that made perfect contact cooled faster than the temperature at the center. 


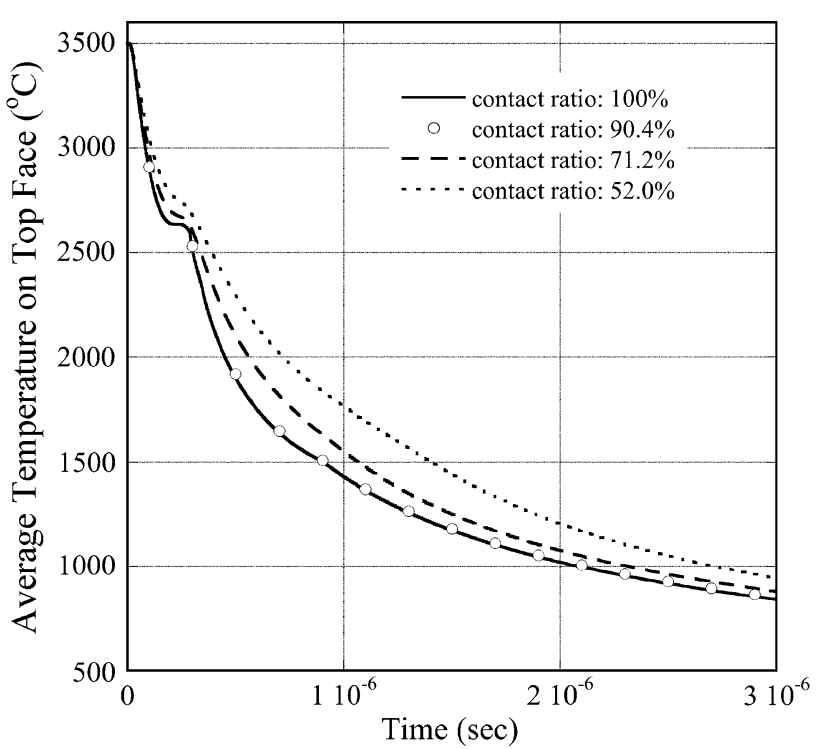

Fig. 8 Average temperature on top face of splat for contact ratios of $100,90.4,71.2$, and $52.0 \%$ with the passage of time

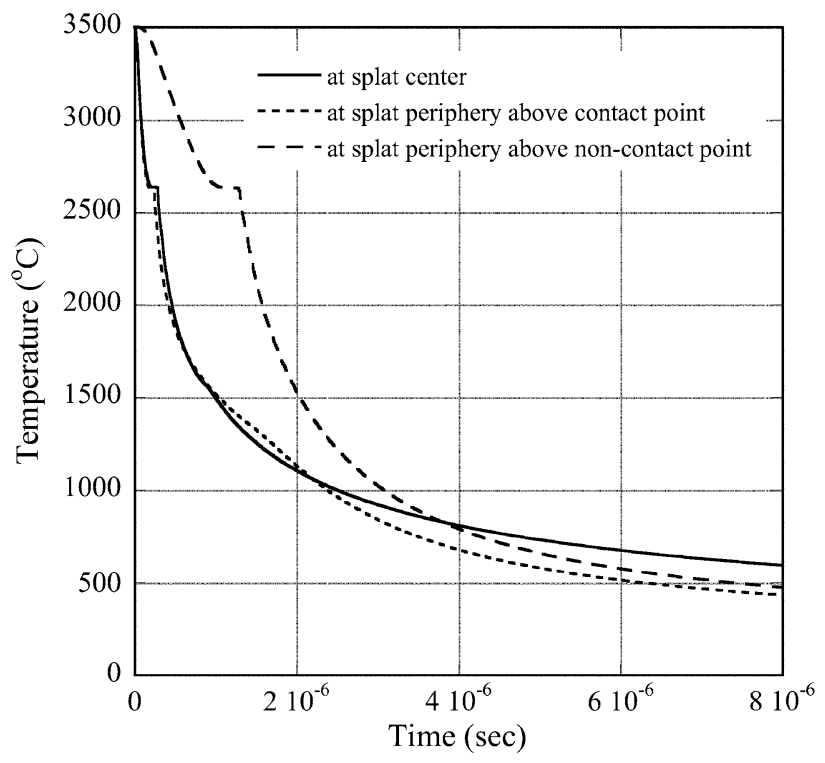

Fig. 9 Variation with respect to time of the top face temperature at the center and periphery above contact and noncontact point for the splat having $52.0 \%$ contact

As for the validity of our splat morphology and cooling model, the authors compared their calculated results with experimental results conducted by McDonald et al., who have reported that the cooling rate of Mo splat on a preheated Inconel substrate was $22 \times 10^{7} \mathrm{~K} / \mathrm{s}$ at the splat temperature of $2300{ }^{\circ} \mathrm{C}(\operatorname{Ref} 12)$. In the model, the cooling rates of Mo splat on $\mathrm{Fe}$ substrate were $354 \times 10^{7}$ and $158 \times$ $10^{7} \mathrm{~K} / \mathrm{s}$ at $2250{ }^{\circ} \mathrm{C}$ of splat temperature when the contact ratios were 100 and $52.0 \%$, respectively. The cooling rate even in the case of $52.0 \%$ contact was one digit larger than that of Mo splat on Inconel in McDonald's experiments.

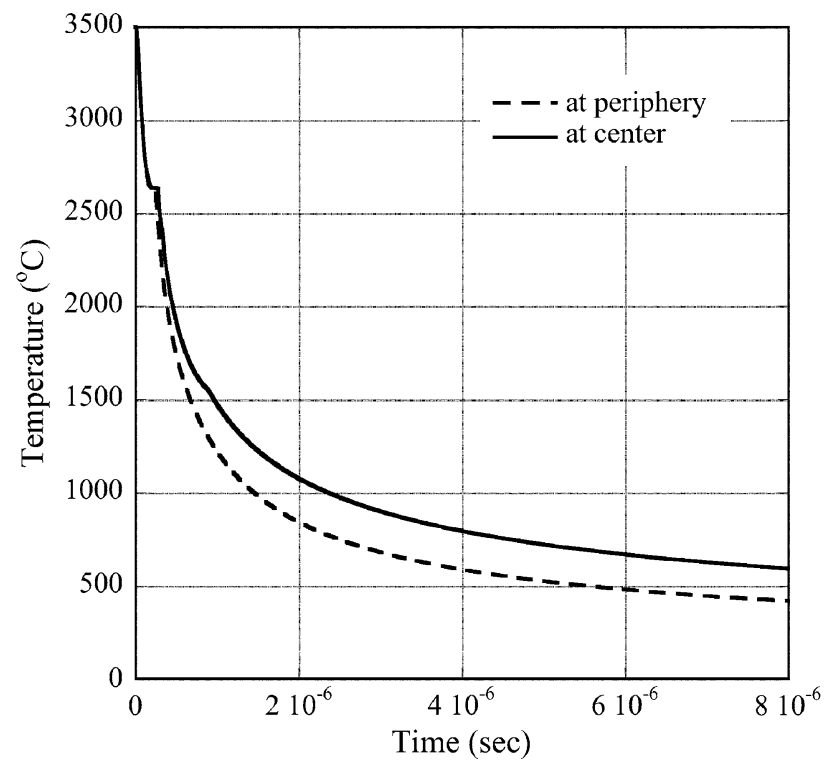

Fig. 10 Variation with respect to time of the top face temperature at the center and periphery for the splat having a contact ratio of $100 \%$

Both cooling curves were similar, although these cooling rates were different. More experimental results on splat cooling are necessary to appreciate precisely the model since cooling rates depend on many factors such as the microstructure of the boundary between a splat and a substrate, splat thickness and diameter, substrate materials, and temperature.

\section{Summary and Conclusions}

A splat/substrate interface model was created by analyzing the morphology of $\mathrm{Ni}, \mathrm{Al}$, and Mo splats sprayed onto glass using a plasma torch. The splats contained many fine lines, or microscopic trenches, on the boundaries between the glass substrate and the splats. The model was characterized by grouping many radial lines into a number of fine trenches, or ditches, on the splat bottom for mathematical modeling and computation. The assumptions of the model were (1) that the trenches were filled with ambient gas that acted as heat resistance during the splat cooling, and (2) that the boundary conditions on the interfaces between the gas trapped in the trenches and the splat, or the substrate, were only conductive, such that radiative and convective heat transfers inside the trenches were not taken into consideration in the computational simulations of the splat cooling process.

The splat cooling rates depended significantly on the ratios of noncontact areas occupied by the trenches filled with ambient gas. The average temperature on the top face of the splat that had more noncontact areas fell more slowly than that of the splat with fewer noncontact areas. The temperature on the top face above a trench cooled much slower than that above a contact position. The temperature 
gap between the positions above the trench and the contact point was more than $1000{ }^{\circ} \mathrm{C}$ in the case of the splat in which the trench had $10^{\circ}$ of central angle. The images of temperature patterns on the top faces were the same as the distribution of trenches in the splats. The simulation results showed that the trapped ambient gas on the boundary between the splat and the substrate plays a critical role in the splat cooling process. Further research on the morphology of the splat/substrate interfaces is needed to clarify how the microstructure of the boundary is formed in order to further understand the cooling processes.

\section{Open Access}

This article is distributed under the terms of the Creative Commons Attribution Noncommercial License which permits any noncommercial use, distribution, and reproduction in any medium, provided the original author(s) and source are credited.

\section{References}

1. L. Bianchi, A.C. Leger, M. Vardelle, A. Vardelle, and P. Fauchais, Splat Formation and Cooling of Plasma-Sprayed Zirconia, Thin Solid Films, 1997, 305, p 35-47

2. M.F. Bahbou, I. Choquet, and P. Nylén, Thermal Spray 207: Global Coating Solutions, B.R. Marple, M.M. Hyland, Y.-C. Lau, C.-J. Li, R.S. Lima, and G. Montavon, Ed., ASM International, 2007

3. Y. Arata, A. Ohmori, and C.-J. Li, Study on the Structure of Plasma Sprayed Ceramic Coating by Using Copper Electroplating, Proceedings of International Symposium on Advanced Thermal Spray Technology and Allied Coatings, 1988, p 205-210
4. S. Kuroda, T. Fukushima, and S. Kitahara, Significance of the Quenching Stress in the Cohesion and Adhesion of Thermal Sprayed Coatings, Proceedings of the International Thermal Spray Conference \& Exposition, 1992, p 903-909

5. M. Fukumoto, S. Katou, and I. Okane, Splat Behavior of Plasma Sprayed Particles on Flat Substrate Surface, Proceedings of the 14th International Thermal Spray Conference, 1995, p 353-358

6. M. Fukumoto, Y. Huang, and M. Ohwatari, Flattening Mechanism in Thermal Sprayed Particle on Flat Substrate, Proceedings of the 15th International Thermal Spray Conference, 1998, p 401406

7. C.-J. Li, Effect of the Surface Adsorbates on the Morphology of Plasma-Sprayed Splats, Proceedings of the International Thermal Spray Conference, 2005, p 311-319

8. H. Li, H.-L. Liao, S. Costil, and C. Coddet, Effects of Substrate Surface Condition on the Flattening Behavior of Impinging Splat, Proceedings of the International Thermal Spray Conference, 2005, p 777-784

9. R. Dhiman, A.G. McDonald, and S. Chandra, Predicting Splat Morphology in a Thermal Spray Process, Surf. Coat. Technol., 2007, 201, p 7789-7801

10. H.R. Salimijazi, L. Pershin, T.W. Coyle, J. Mostaghimi, L. Rosenzweig, and E. Moran, Effect of Substrate Temperature and Droplet Characteristics on Plasma Sprayed Zirconia Splats, Proceedings of the International Thermal Spray Conference, 2006

11. A. McDonald, S. Chandra, M. Lamontagne, and C. Moreau, Photographing Impact of Plasma-Sprayed Particles on Metal Substrates, Proceedings of the International Thermal Spray Conference, 2006

12. A. McDonald, C. Moreau, and S. Chandra, Thermal Contact Resistance Between Plasma-Sprayed Particles and Flat Surfaces, Int. J. Heat Mass Transf., 2007, 50, p 1737-1749

13. M. Amara, V. Timchenco, M. El Ganaoui, E. Leonardi, and G. de Vahl Davis, A 3D Computational Model of Heat Transfer Coupled to Phase Change in Multilayer Materials with Random Thermal Contact Resistance, Int. J. Therm. Sci., 2009, 48, p 421427

14. J. Crank, Free and Moving Boundary Problems, Oxford University Press, New York, 1984, p 217-234 